\title{
A review of ultra-short soliton pulse generation using InGaAsP/InP microring resonator (MRR) system
}

\author{
I. S. Amiri ${ }^{1, ~ *}$, H. Ahmad ${ }^{1}$, Hamza M. R. Al-Khafaji ${ }^{2}$ \\ ${ }^{1}$ Photonics Research Centre, University of Malaya (UM), 50603 Kuala Lumpur, Malaysia \\ ${ }^{2}$ Wireless Communication Centre, Faculty of Electrical Engineering, Universiti Teknologi Malaysia (UTM), 81310 UTM Skudai, Johor, \\ Malaysia
}

Email address:

amiri@um.edu.my (I. S. Amiri), harith@um.edu.my (H. Ahmad), hamza@utm.my (H. M. R. Al-Khafaji)

\section{To cite this article:}

I. S. Amiri, H. Ahmad, Hamza M. R. Al-Khafaji. A Review of Ultra-Short Soliton Pulse Generation Using InGaAsP/InP Microring Resonator (MRR) Systems. American Journal of Networks and Communications. Special Issue: Recent Progresses in Optical Code-Division Multiple-Access (OCDMA) Technology. Vol. 4, No. 2-1, 2015, pp. 6-17. doi: 10.11648/j.ajnc.s.2015040201.12

\begin{abstract}
System of microring resonators (MRRs) incorporating with an add/drop MRR system are presented to generate single and multi-temporal and spatial ultra-short soliton pulses applicable in optical soliton communications. The chaotic signals caused by the nonlinear condition could be generated and propagated within the system. The Kerr effect in the MRR system induces the nonlinearity condition. The proposed MRR systems are used to generate ultra-short soliton pulse within the system. Using the appropriate MRR parameters, ultra-short spatial and temporal signals are generated spreading over the spectrum. In this work, narrow soliton pulses could be localized within the proposed systems. Here soliton pulses of 0.7 ps, $0.83 \mathrm{fs}$ and $19 \mathrm{pm}$ are generated using series of MRRs connected to an add/drop MRR system. The nonlinear refractive index is $n_{2}=2.2 \times 10^{-17} \mathrm{~m}^{2} / \mathrm{W}$. Using the panda ring resonator system, the ultra-short soliton pulses with full width at half maximum (FWHM) and free spectral range (FSR) of $5 \mathrm{MHz}$ and $2 \mathrm{GHz}$, were generated the throughput port. The output signals pulses with FWHM of $10 \mathrm{MHz}$ and FSR of $2 \mathrm{GHz}$ could be obtained at the drop port of the system. As second results using this system, multi-carrier soliton pulses with FWHM=20 MHz are localized within this system with respect to 20,000 roundtrips of the input pulse. Localized optical tweezers could be generated using the half-Panda MRR system, where the peaks have FWHM and FSR of $8.9 \mathrm{~nm}$ and $50 \mathrm{~nm}$ respectively. The nonlinear refractive index was selected to $n_{2}=2.5 \times 10^{-17} \mathrm{~m}^{2} / \mathrm{W}$.
\end{abstract}

Keywords: Microring Resonator (MRR), Ultra-Short Soliton, Spatial and Temporal Soliton, Kerr Effect

\section{Introduction}

Ultra-short soliton generation is very attractive especially when it uses quantum cryptography in an optical communication network, which is reported by Amiri [1-4]. A spectrum of light over a broad range can be generated, thus an optical soliton pulse is advised as a powerful laser pulse which can be utilized to generate chaotic filter features when spreading within microring resonators (MRRs) [5-8]. Therefore, the capacity of the transmission data can be secured and increased when the chaotic packet switching is utilized provided using this technique, [9-11]. In this study, we propose a systems of MRRs that uses ultra-short localized spatial and temporal soliton pulses to form the high capacity communication [12-16]. The device parameters are simulated associating to the practical device parameters [17-21]. Orthogonal frequency division multiplexing (OFDM) is a combination of modulation and multiplexing [22-25]. Modulation refers to the process of changing the carrier phase, frequency, amplitude, or their combination with a modulated signal that typically contains information to be transmitted [26-29]. However, the aim of multiplexing is to share a bandwidth. Single-carrier modulation is a technology that modulates information onto only one carrier [30-33]. The main problem of this technology is satisfying the need for high bandwidth in fixed spectrum limits of one single-carrier [34-38]. High data rate in one carrier causes a high symbol rate. As the duration of one symbol or bit becomes smaller, the system becomes more susceptible to loss of information from impulse noise, signal reflections, and other impairments [39-43]. These impairments can impede the ability to recover information sent. In addition, as the bandwidth used by a single-carrier system increases, the susceptibility to interference from other continuous signal sources becomes greater. This type of interference is commonly labelled as a 
carrier wave $(\mathrm{CW})$ or frequency interference [44-47]. DarkGaussian soliton controls within a semiconductor add/drop multiplexer has numerous applications in optical communication [48-53]. Nano optical tweezers technique has become a powerful tool for manipulation of micrometer-sized particles/photons in three spatial dimensions [54-62]. It has the unique ability to trap and manipulate molecules/photons at mesoscopic scales with widespread applications in biology and physical sciences [63-69]. The output is achieved when the high optical field is set up as an optical tweezers [70-73]. For communication's application purposes, the optical tweezers can be used to generate entangled photon within the proposed network system [74-78].

Internet security becomes an important function in the modern internet service. However, the security technique known as quantum cryptography has been widely used and investigated in many applications, using ultra-short optical solitons [79-83]. Amiri et al, have proposed the new design of optical switching used in optical communication systems [84-89]. This method uses nonlinear behaviour of light in MRR which can be applicable for high-capacity transmission and switching [90-94]. Transmission of all-optical OFDM can be implemented by generating multiple optical subcarriers, separating these subcarriers via optical devices, and finally modulating each subcarrier separately [95-97]. Optical carrier generation thus constitutes the basic building block to implement OFDM transmission fully in the optical domain [98-101]. The MRR system provides a viable means to generate this building block that represents the generation of the necessary multi-carriers [102-104]. A soliton solution of the nonlinear wave equation is always stable over a long distance link, and this stability of soliton signals is even more remarkable than the possibility of balancing dispersion and non-linearity [105-110]. One important aspect of the MRR system is that suitable tuning of the system parameters allows for desired soliton carriers with specific key characteristics, such as full width at half maximum (FWHM) and stability, to be obtained at the drop/through ports of the system [111-116].

\section{Picosecond Soliton Pulses Generation}

The schematic diagram of the proposed system is shown in Fig. 1. A soliton pulse with $20 \mathrm{~ns}$ pulse width, peak power at $500 \mathrm{~mW}$ is input into the system. The suitable ring parameters are used, for instance, ring radii $R_{1}=10 \mu \mathrm{m}$, $R_{2}=5 \mu \mathrm{m}$, and $R_{3}=4 \mu \mathrm{m}$. In order to make the system associate with the practical device, the selected parameters of the system are fixed to $\lambda_{0}=1.55 \mu \mathrm{m}, n_{0}=3.34$ (InGaAsP/InP) [117121], $A_{\text {eff }}=0.50,0.25 \mu \mathrm{m}^{2}$ and $0.12 \mu \mathrm{m}^{2}$ for the different radii of MRRs respectively [122-124], $\alpha=0.5 \mathrm{dBmm}^{-1}, \gamma=0.1$ [125127]. The coupling coefficient $(\kappa)$ of the MRR ranged from 0.50 to 0.975 [128-130].

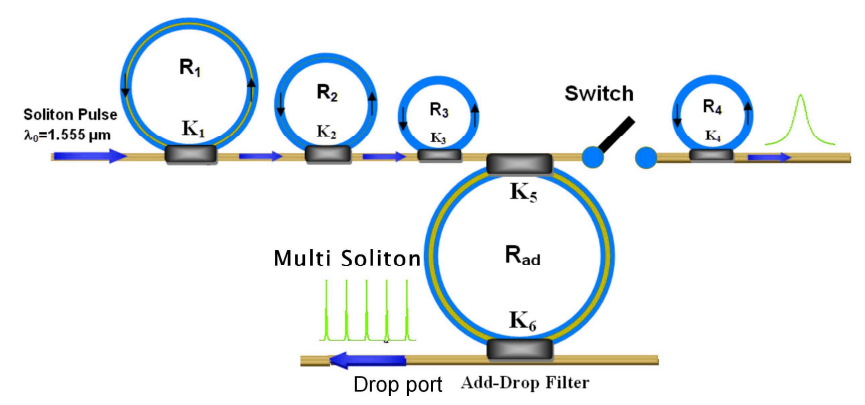

Fig. 1. Schematic diagram of soliton pulse generation, $R s$, ring radii and $\kappa s$, coupling coefficients

The soliton pulse is introduced into the proposed system. The input optical field $\left(E_{\text {in }}\right)$ can be in the form of bright soliton (equation 1), dark soliton (equation 2) and Gaussian laser beam (equation 3) [131-136]. Here, the bright soliton pulse is input into the system. The input optical field $\left(E_{\text {in }}\right)$ of the bright soliton, dark soliton and Gaussian laser beam are given by:

$$
\begin{gathered}
E_{\text {in }}=A \sec h\left[\frac{T}{T_{0}}\right] \exp \left[\left(\frac{z}{2 L_{D}}\right)-i \omega_{0} t\right] \\
E_{\text {in }}=A \tanh \left[\frac{T}{T_{0}}\right] \exp \left[\left(\frac{z}{2 L_{D}}\right)-i \omega_{0} t\right], \\
E_{\text {in }}(t)=A \exp \left[\left(\frac{z}{2 L_{D}}\right)-i \omega_{0} t\right]
\end{gathered}
$$

$A$ and $z$ are the optical field amplitude and propagation distance, respectively $[137,138] . T$ is a soliton pulse propagation time in a frame moving at the group velocity [139-141], $T=t-\beta_{1} \times z$, where $\beta_{1}$ and $\beta_{2}$ are the coefficients of the linear and second order terms of Taylor expansion of the propagation constant [142-144]. $L_{D}=T_{0}^{2} /\left|\beta_{2}\right|$ is the dispersion length of the soliton pulse [145, 146]. The frequency shift of the soliton is $\omega_{0}$.

This solution reports a pulse that maintains its temporal width invariance as it spreads, and thus is called a temporal soliton [147-149]. When a soliton peak intensity $\left(\beta_{2} / \Gamma T_{0}^{2} \mid\right)$ is established, then $T_{o}$ is recognized [150-152]. For the soliton pulse in the MRR system, a balance should be accomplished between the dispersion length $\left(L_{\mathrm{D}}\right)$ and the nonlinear length $\left(L_{N L}=1 / \Gamma \varphi_{N L}\right)$ [153-155], where $\Gamma=n_{2} \times k_{0}$, is the length scale over which dispersive or nonlinear effects makes the beam gets wider or narrower $[156,157]$.

Since for a soliton pulse, there is a balance between dispersion and nonlinear lengths, therefore $L_{\mathrm{D}}=L_{\mathrm{NL}}[158,159]$. Whenever light spreads within the nonlinear medium, the refractive index (n) of light within the medium is contributed by [160-162].

$$
n=n_{0}+n_{2} I=n_{0}+\left(\frac{n_{2}}{A_{\text {eff }}}\right) P,
$$


where $n_{0}$ and $n_{2}$ represent the linear and nonlinear refractive indices, respectively. $I$ and $P$ are the optical intensity and powers, respectively $[163,164]$. The effective mode core area of the device is introduced by $A_{\text {eff. }}$ For the MRR and $\mathrm{NRR}$, the effective mode core areas range 0.50 to $0.10 \mu \mathrm{m}^{2}$. When a soliton pulse is input and propagated within a MRR as shown in Fig. 1, the resonant output can be performed, hence, the normalized output of the light field is defined by the ratio between the output and input fields presented by $E_{\text {out }}(\mathrm{t})$ and $E_{\text {in }}(\mathrm{t})$ in each roundtrip, and can be expressed as [165-168]

$$
\left|\frac{E_{\text {out }}(t)}{E_{\text {in }}(t)}\right|^{2}=(1-\gamma)\left[1-\frac{\left(1-(1-\gamma) x^{2}\right) \kappa}{(1-x \sqrt{1-\gamma} \sqrt{1-\kappa})^{2}+4 x \sqrt{1-\gamma} \sqrt{1-\kappa} \sin ^{2}\left(\frac{\phi}{2}\right)}\right]
$$

The equation 5 suggests that a MRR in the special case is very similar to a Fabry-Perot cavity, having an input and an
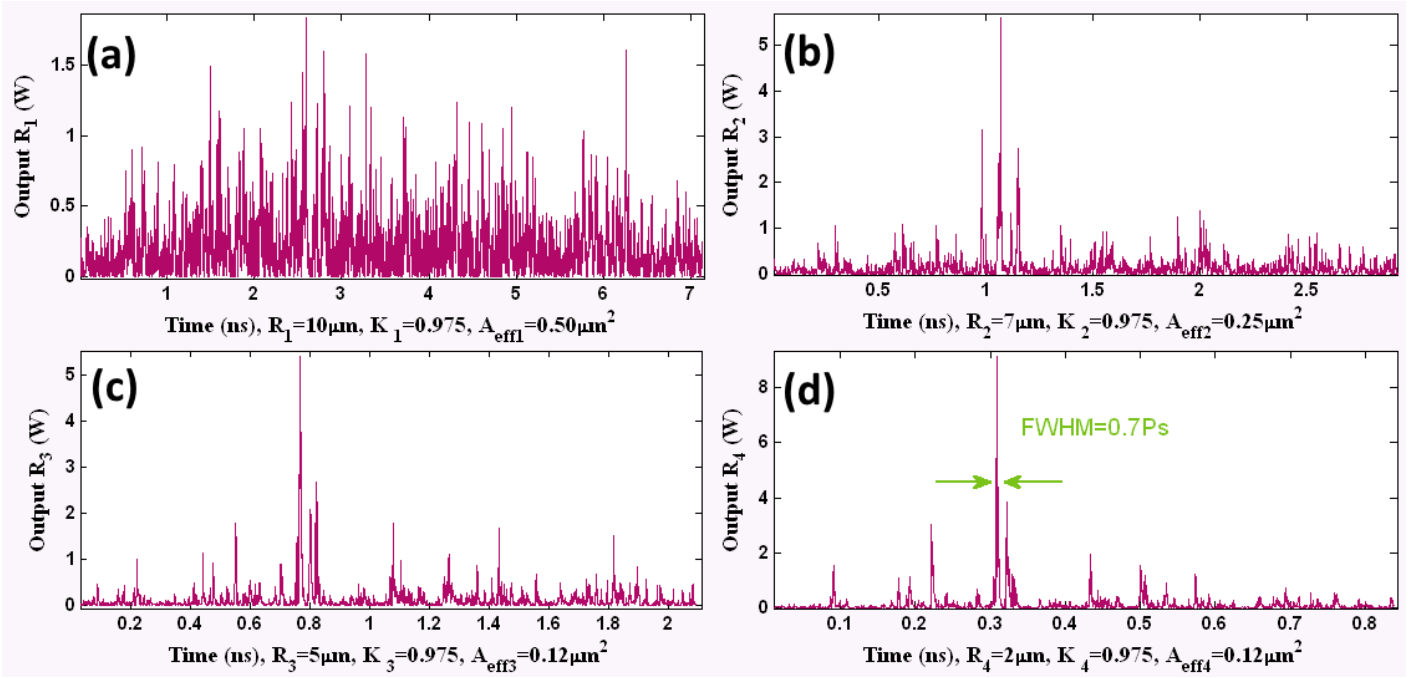

Fig. 2. Results obtained when temporal soliton is localized within a MRR, where (a): Chaotic signals from $R_{l}$, (b): Chaotic signals from $R_{2}$, (c): temporal soliton, (d): temporal soliton with FWHM of $0.7 \mathrm{ps.}$
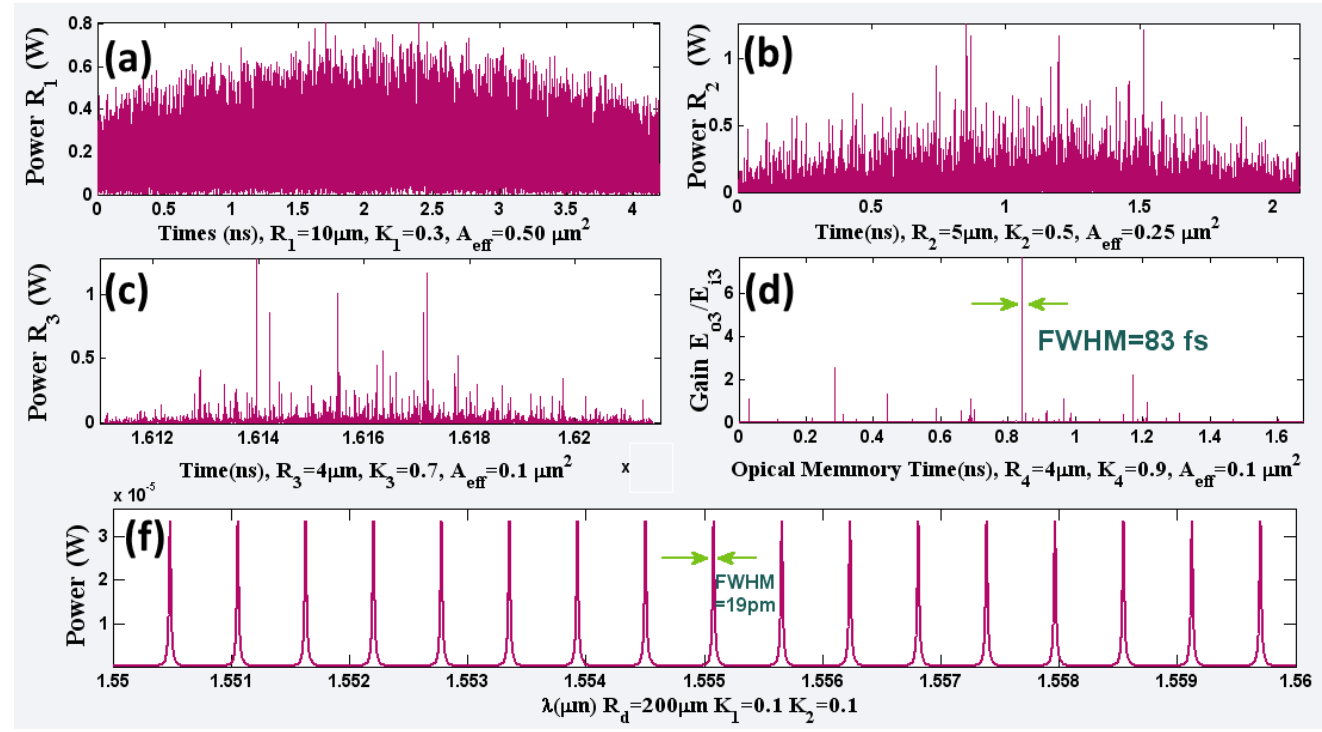

Fig. 3. Results of temporal and spatial soliton generation, where (a): Chaotic signals from $R_{l},(b)$ : Chaotic signals from $R_{2}$, $(c)$ : filtering signals, $(d)$ : Temporal soliton with FWHM of $83 \mathrm{fs}$, (e): Spatial soliton with FWHM=19 pm output mirrors with a field reflectivity, $(1-\kappa)$, and a fully reflecting mirror $[169,170] . \kappa$ is the coupling coefficient, and $x=\exp (-\alpha L / 2)$ symbolizes a roundtrip loss coefficient, $\Phi_{0}=k L n_{0}$ and $\Phi_{\mathrm{NL}}=k L n_{2}\left|E_{\mathrm{in}}\right|^{2}$ are the linear and nonlinear (171, 172], $k=2 \pi / \lambda$ is the wave propagation number in a vacuum. Where $L$ and $a$ are the waveguide 174]. In this work, the iterative method is brought in to obtain the results as shown in equation 3, likewise, when the output field is associated and input into the other ring resonators. The nonlinear refractive index is $n_{2}=2.2 \times 10^{-17}$ $\mathrm{m}^{2} / \mathrm{W}$. In this case, the waveguide loss utilized is $0.5 \mathrm{dBmm}^{-1}$. As shown in Figure 2, the signal is chopped into a smaller signals spreading over the spectrum. The attenuation of the maintain the constant output gain. 
Figure 3 demonstrates the results while temporal and spatial optical soliton pulses are localized within a MRR and add/drop MRR systems with 20,000 roundtrips, thus the optical pulse of $83 \mathrm{fs}$ can be generated. Here, the ring radii are $R_{1}=10 \mu \mathrm{m}, R_{2}=5 \mu \mathrm{m}, R_{3}=4 \mu \mathrm{m}, R_{4}=4 \mu \mathrm{m}$ and $R_{\mathrm{ad}}=200$ $\mu \mathrm{m}$ with coupling coefficient of $\kappa_{1}=0.3, \kappa_{2}=0.5, \kappa_{3}=0.7$, $\kappa_{4}=0.9, \kappa_{5}=0.1$ and $\kappa_{6}=0.1$.

\section{Soliton Generation in Frequency domain for Communication Application}

The system of soliton frequency band generation is shown in Figure 4. Here, series of ring resonators are connected to a panda ring resonator system. The filtering process of the input soliton pulses is performed via the ring resonators, where frequency band ranges $40-60 \mathrm{GHz}$ can be obtained via the output signals of the panda ring resonator system. The soliton pulse shown by equation 1 is introduced into the nonlinear system.

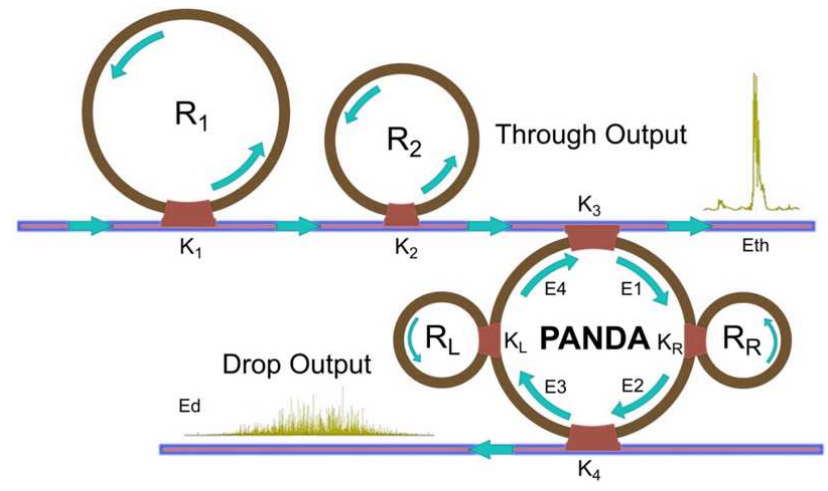

Fig. 4. Optical frequency band generation system using a panda ring resonator connected to a series of MRRs

A frequency soliton pulse can be formed and trapped within the panda ring resonator system with suitable ring parameters. The centred ring of the panda ring resonator system has a radius of $100 \mu \mathrm{m}$ and coupling coefficients of $\kappa_{3}=0.35$ and $\kappa_{4}=0.30$, where the right and left rings have radii of $18 \mu \mathrm{m}$ and $8 \mu \mathrm{m}$, respectively. The effective core areas of the right and left rings are $A_{\text {eff } 1}=A_{\text {eff } 2}=0.25 \mathrm{\mu m}^{2}$, where the coupling coefficients have been selected to $\kappa_{R}=0.22$ and $\kappa_{L}=0.10$. Filtering of the interior soliton signals can be performed when the pulses pass through the couplers, $\kappa_{3}$ and $\kappa_{4}$. The output signals from the throughput and drop ports of the system can be seen in Figure 5, where soliton range of 40-60 GHz are generated and used in many optical communication applications, such as wireless personal area networks (WPANs) and wireless local area networks (WLANs). The throughput output $\left(E_{\mathrm{th}}\right)$ shows localized ultrashort soliton pulses with an FWHM and free spectral range (FSR) of $5 \mathrm{MHz}$ and $2 \mathrm{GHz}$, respectively, where soliton pulses at frequencies of $50 \mathrm{GHz}$ and $52 \mathrm{GHz}$ are generated. The drop output signals expressed by $E_{\mathrm{d}}$ are shown in Figure 5(b-c), where, pulses with FWHM of $10 \mathrm{MHz}$ and FSR of 2 $\mathrm{GHz}$ are obtained.
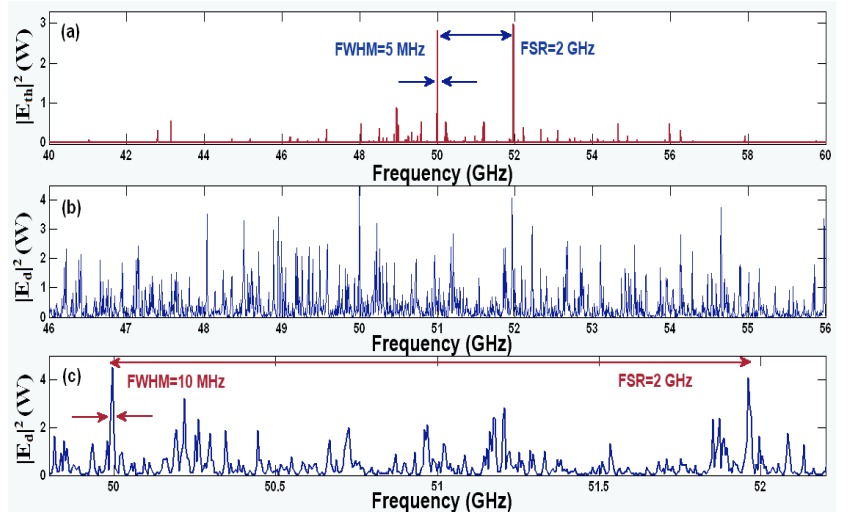

Fig. 5. Results of localized solitons: (a): throughput output signal with $F W H M=5 \mathrm{MHz}$ and $F S R=2 \mathrm{GHz},(b)$ : chaotic soliton pulses, (c): expansion of the soliton pulses ranges $50-52 \mathrm{GHz}$ with $\mathrm{FWHM}=10 \mathrm{MHz}$ and $F S R=2$ $\mathrm{GHz}$

A bright soliton with a central frequency of $92.5 \mathrm{GHz}$ and power of $2 \mathrm{~W}$ is introduced into the first MRR. The results of the chaotic signal generation are shown in Figure 6. The rings' radii and coupling coefficients are $R_{1}=6 \mu \mathrm{m}, \kappa_{1}=0.3$, $R_{2}=4 \mu \mathrm{m}$ and $\kappa_{2}=0.3$. The ring of the Panda ring resonator system has a radius of $120 \mu \mathrm{m}$ and coupling coefficients of $\kappa_{3}=0.3$ and $\kappa_{4}=0.5$, where the right and left rings have the same radii of $R_{R}=3 \mu \mathrm{m}$ and $R_{L}=3 \mu \mathrm{m}$. The effective core areas of the rings are $A_{e f f R}=A_{\text {eff } L}=0.10 \mu \mathrm{m}^{2}$, where the coupling coefficients have been selected to $\kappa_{R}=0.2$ and $\kappa_{L}=0.1$. The wave-guided and fractional coupler intensity losses are $\alpha=0.5 \mathrm{dBmm}-1$, and $\gamma=0.1$ respectively. The through put output shows localized narrow bandwidth soliton pulses with FWHM and FSR of $3 \mathrm{MHz}$ and $200 \mathrm{MHz}$, respectively, where soliton pulses at frequencies of $92.6,92.8$ and $93 \mathrm{GHz}$ are generated. The drop port output signals are shown in Figure 6(c-d), where multi-soliton pulses with FWHM of 11 $\mathrm{MHz}$ and FSR of $188 \mathrm{MHz}$ could be generated.

As it can be concluded from the results, the efficiency of this system can be evaluated by the output solitonic carrier signal generated by the MRRs. Long distance fiber communication link is implemented using this method and can be integrated to short distance indoor wireless link for ultra-high data rate transmission.
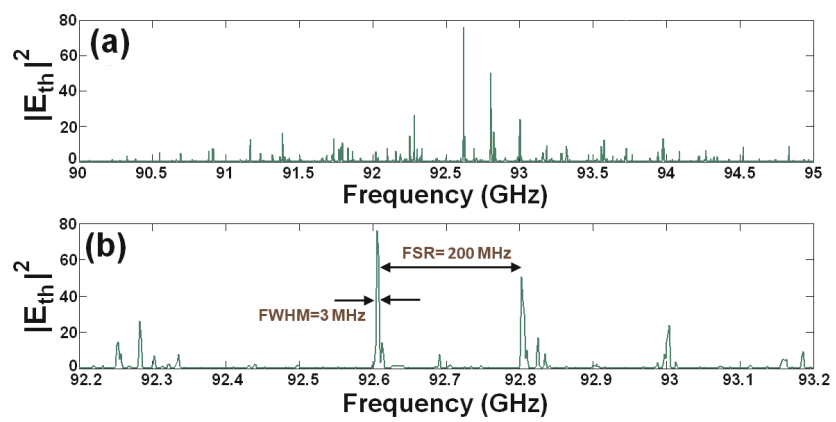

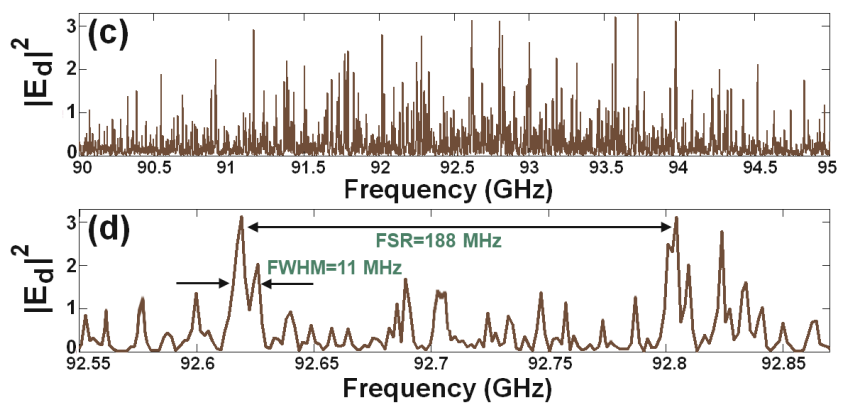

Fig. 6. (a-b) throughput output signal $\left(W / \mu m^{2}\right)$ with $F W H M=3 \mathrm{MHz}$ and $F S R=200 M H z,(c-d)$ drop port multi-solitons output signal $\left(W / \mu m^{2}\right)$ with $F W H M=11 \mathrm{MHz}$ and $F S R=188 \mathrm{MHz}$

\section{Ultra-Short Soliton Tweezers Generation}

The array of dark soliton pulses expressed by equation 2 are introduced into the input port half-Panda MRR system shown in Figure (7). This system consists of an add/drop MRR system connected to a smaller ring resonator on the right side.

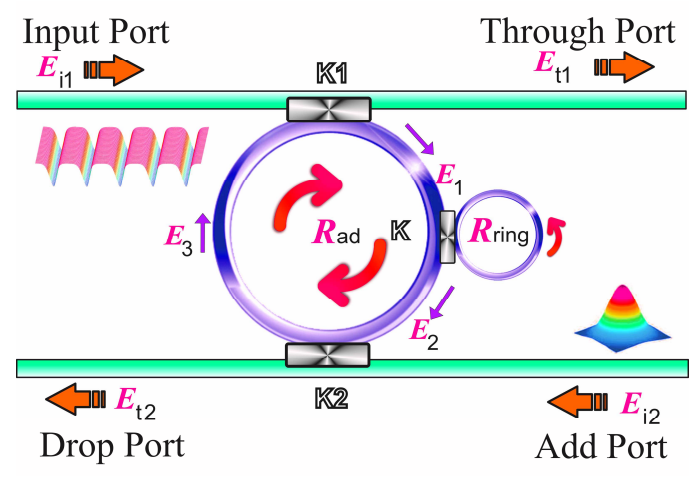

Fig. 7. A schematic diagram of Half-Panda MRR system

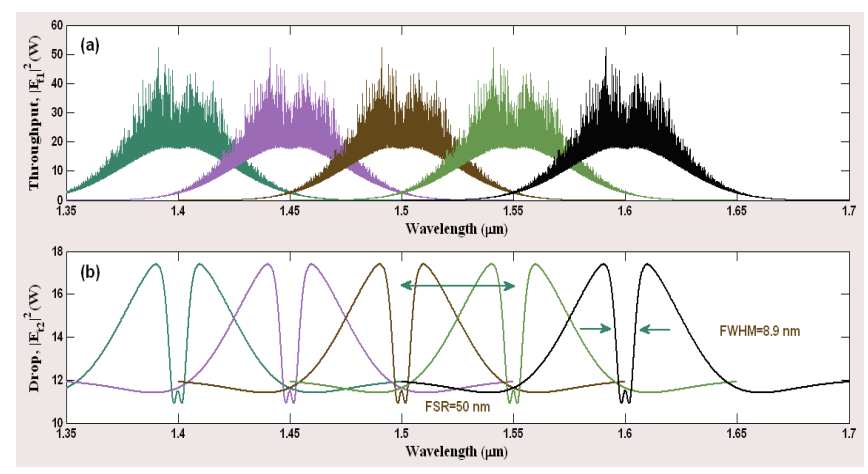

Fig. 8. (a): Through port chaotic output signals (b): drop port output with $F W H M=8.9$ and $F S R=50 \mathrm{~nm}$

Input optical dark solitons and Gaussian laser beam (input into the add port) with powers $2 \mathrm{~W}$ and $1 \mathrm{~W}$ respectively are inserted into the half-Panda MRR system. The add/drop MRR system has radius of $R_{\mathrm{ad}}=15 \mu \mathrm{m}$ where the coupling coefficients are $\kappa_{1}=0.35$ and $\kappa_{2}=0.25$. The dark solitons are propagating inside the half-Panda MRR system with central wavelengths of $\lambda_{0}=1.4 \mu \mathrm{m}, 1.45 \mu \mathrm{m}, 1.5 \mu \mathrm{m}, 1.55$ $\mu \mathrm{m}, 1.6 \mu \mathrm{m}$. In order to make the system associate with the practical device (InGaAsP/InP), the selected parameters of the system are fixed to $n_{0}=3.34$ and $n_{2}=2.5 \times 10^{-17} \mathrm{~m}^{2} / \mathrm{W}$. Filtered and clear optical tweezers are seen in figure 8 where the peaks have FWHM and FSR of $8.9 \mathrm{~nm}$ and $50 \mathrm{~nm}$ respectively. In the case of communication networks, generation of narrower signals is recommended to compensate the fiber loss and system's attenuation.

By using suitable dark-Gaussian soliton input powers, tunable optical tweezers can be controlled. This provides the entangled photon as the dynamic optical tweezers probe. The required data can be retrieved via the through and drop ports of the add/drop MRR. High capacity data transmission can be obtained by using more wavelength carriers. The advantage of this study is that ultra-short nano optical tweezers can be generated and transmitted via a network system thus improving the sensitivity and capacity.

\section{Multi-Carries Soliton Generation for Wired/Wireless Optical Communication Systems}

Using the system shown by Figure 1, the optical soliton carrier can be generated. Figure 9 shows the results when soliton pulses are localized within the MRR and add/drop MRR systems with 20,000 roundtrips, where the soliton pulses with FWHM $=20 \mathrm{MHz}$ could be generated as result of the fourth ring resonator shown in Figure 9(d). The output results from the drop port of the system can be seen in the Figure 9(e-f). Here, the ring radii are $R_{1}=15 \mu \mathrm{m}, R_{2}=9 \mu \mathrm{m}$, $R_{3}=6 \mu \mathrm{m}, R_{4}=6 \mu \mathrm{m}$ and $R_{\mathrm{ad}}=100 \mu \mathrm{m}$ having coupling coefficients of $\kappa_{1}=0.98, \kappa_{2}=0.98, \kappa_{3}=0.96, \kappa_{4}=0.92$, $\kappa_{5}=0.1$ and $\kappa_{6}=0.1$. The nonlinear refractive index is $2.4 \times 10^{-17} . A_{\text {eff1 }}\left(\mu \mathrm{m}^{2}\right)=0.50, A_{\text {eff2 }}\left(\mu \mathrm{m}^{2}\right)=0.25$ and $A_{\text {eff3-4 }}$ $\left(\mu \mathrm{m}^{2}\right)=0.10$.
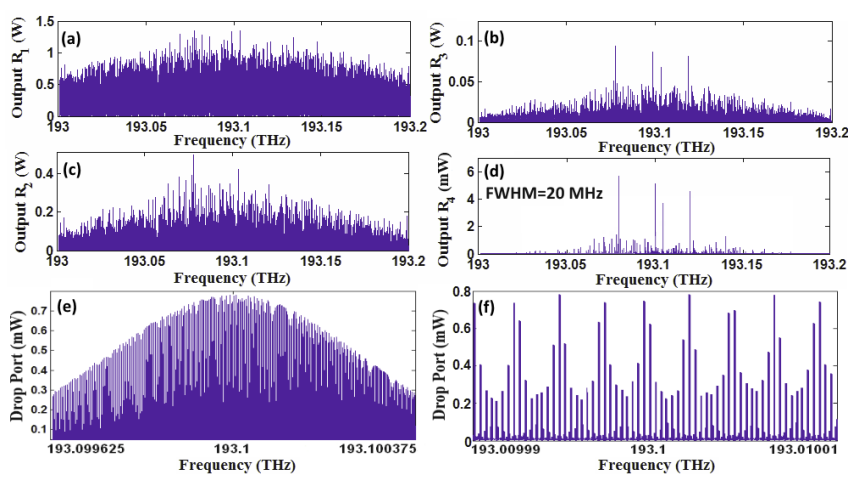

Fig. 9. (a): output from first ring resonator, (b): output from second ring resonator, (c): output from third ring resonator, $(d)$ : multi-solitons output from the drop port, (e): multi-carriers generation

Thus, filtering of the input pulse within the system allowed for generation of single- and multi-soliton pulses to be used in a multiple-input and multiple-output (MIMO)-OFDM communication systems. 


\section{Conclusion}

We have proposed an interesting concept of the ultra-short soliton pulse generation using microring resonators (MRRs), in which the single and multiple temporal and spatial soliton pulses could be achieved. The balance established between the dispersion and nonlinear lengths of the soliton pulse presents the soliton behavior known as self-phase modulation, which introduces the optical output constant, meaning that the light pulse can be localized coherently within the nanowaveguide. We have demonstrated that a large bandwidth of the arbitrary soliton pulses can be generated and compressed within a microring waveguide. The chaotic signal generation by means of a soliton pulse in the nonlinear MRRs has been presented. Selected light pulse can be localized and used to perform the high capacity of optical communication due to generate ultra-short bandwidth of the pulses. Localized spatial and temporal soliton pulse are useful to generate optical communication signals applicable for wired/wireless networks. As an application, the classical information and security codes can be formed by using the temporal and spatial soliton pulses, respectively.

\section{Acknowledgements}

Amiri and Ahmad would like to acknowledge the financial support from University Malaya/MOHE under grant number UM.C/625/1/HIR/MOHE/SCI/29 and RU002/2013.

\section{References}

[1] S. E. Alavi, I. S. Amiri, S. M. Idrus, ASM Supa'at, J. Ali \& P. P. Yupapin, (2014) "All Optical OFDM Generation for IEEE802.11a Based on Soliton Carriers Using MicroRing Resonators ", IEEE Photonics Journal, 6(1),

[2] Iraj Sadegh Amiri \& Harith Ahmad, Optical Soliton Communication Using Ultra-Short Pulses. USA: Springer, 2014.

[3] J. Ali, I. S. Amiri, A. Jalil, A. Kouhnavard, B. Mitatha \& P. Yupapin, (2010) "Quantum internet via a quantum processor", presented at the International Conference on Photonics (ICP 2010), Langkawi, Malaysia

[4] I. S. Amiri, A. Nikoukar, J. Ali \& P. P. Yupapin, (2012) "UltraShort of Pico and Femtosecond Soliton Laser Pulse Using Microring Resonator for Cancer Cells Treatment", Quantum Matter, 1(2), 159-165.

[5] J. Ali, K. Raman, A. Afroozeh, I. S. Amiri, M. A. Jalil, I. N. Nawi \& P. P. Yupapin, (2010) "Generation of DSA for security application", presented at the 2nd International Science, Social Science, Engineering Energy Conference (I-SEEC 2010), Nakhonphanom, Thailand.

[6] Amiri, H Ahmad \& MZ Zulkifli, (2014) "Integrated ring resonator system analysis to Optimize the soliton transmission", International Research Journal of Nanoscience and Nanotechnology, 1(1), 002-007.

[7] J. Ali, I. S. Amiri, M. A. Jalil, F. K. Mohamad \& P. P. Yupapin, (2010) "Optical dark and bright soliton generation and amplification", presented at the Nanotech Malaysia, International Conference on Enabling Science \& Technology, KLCC, Kuala Lumpur, Malaysia.

[8] J. Ali, M. Kouhnavard, M. A. Jalil \& I. S. Amiri, (2010) "Quantum signal processing via an optical potential well", presented at the Nanotech Malaysia, International Conference on Enabling Science \& Technology, Kuala Lumpur, Malaysia

[9] I. S. Amiri, S. E. Alavi \& J. Ali, (2013) "High Capacity Soliton Transmission for Indoor and Outdoor Communications Using Integrated Ring Resonators", International Journal of Communication Systems, 28(1), 147160.

[10] IS Amiri \& A Afroozeh, Integrated Ring Resonator Systems, in Ring Resonator Systems to Perform Optical Communication Enhancement Using Soliton, ed USA: Springer, 2014.

[11] D. Gifany, I. S. Amiri, M. Ranjbar \& J. Ali, (2013) "LOGIC CODES GENERATION AND TRANSMISSION USING AN ENCODING-DECODING SYSTEM", International Journal of Advances in Engineering \& Technology (IJAET), 5(2), 37-45

[12] A. Afroozeh, I.S. Amiri, K. Chaudhary, J. Ali \& P. P. Yupapin, Analysis of Optical Ring Resonator, in Advances in Laser and Optics Research, ed New York: Nova Science, 2015.

[13] A. Afroozeh, I. S. Amiri, M. Kouhnavard, M. Bahadoran, M. A. Jalil, J. Ali \& P. P. Yupapin, (2010) "Dark and Bright Soliton trapping using NMRR", presented at the International Conference on Experimental Mechanics (ICEM), Kuala Lumpur, Malaysia.

[14] J. Ali, M. Roslan, M. Jalil, I. S. Amiri, A. Afroozeh, I. Nawi \& P. Yupapin, (2010) "DWDM enhancement in micro and nano waveguide", presented at the AMN-APLOC International Conference, Wuhan, China.

[15] I. S. Amiri, J. Ali \& P. P. Yupapin, (2012) "Enhancement of FSR and Finesse Using Add/Drop Filter and PANDA Ring Resonator Systems", International Journal of Modern Physics $B, 26(04), 1250034$.

[16] I. S. Amiri, (2011), "FWHM Measurement of Localized Optical Soliton", in The International Conference for Nano materials Synthesis and Characterization, Malaysia.

[17] I. S. Amiri, S. E. Alavi \& H. Ahmad, (2015) "Analytical Treatment of the Ring Resonator Passive Systems and Bandwidth Characterization Using Directional Coupling Coefficients ", Journal of Computational and Theoretical Nanoscience (CTN), 12(3),

[18] M. Bahadoran, I. S. Amiri, A. Afroozeh, J. Ali \& P. P. Yupapin, (2011) "Analytical Vernier Effect for Silicon Panda Ring Resonator", presented at the National Science Postgraduate Conference, NSPC Universiti Teknologi Malaysia.

[19] I. S. Amiri, R. Ahsan, A. Shahidinejad, J. Ali \& P. P. Yupapin, (2012) "Characterisation of bifurcation and chaos in silicon microring resonator", IET Communications, 6(16), 2671-2675.

[20] I. S. Amiri \& J. Ali, (2014) "Characterization of Optical Bistability In a Fiber Optic Ring Resonator", Quantum Matter, $3(1), 47-51$.

[21] J. Ali, M. A. Jalil, I. S. Amiri \& P. P. Yupapin, (2010) "Fast and slow lights via an add/drop device", presented at the ICEM, Legend Hotel, Kuala Lumpur, Malaysia. 
[22] IS Amiri, SE Alavi, N Fisal, ASM Supa'at \& H Ahmad, (2014) "All-Optical Generation of Two IEEE802.11n Signals for $2 \times 2$ MIMO-RoF via MRR System", IEEE Photonics Journal, 6(6),

[23] SE Alavi, IS Amiri, H Ahmad, ASM Supa'at \& N Fisal, (2014) "Generation and Transmission of $3 \times 3$ W-Band MIMOOFDM-RoF Signals Using Micro-Ring Resonators", Applied Optics, 53(34), 8049-8054.

[24] I. S. Amiri, S. E. Alavi, Sevia M. Idrus, A. Nikoukar \& J. Ali, (2013) "IEEE 802.15.3c WPAN Standard Using Millimeter Optical Soliton Pulse Generated By a Panda Ring Resonator", IEEE Photonics Journal, 5(5), 7901912.

[25] Iraj Sadegh Amiri, Sayed Esan Alavi, Sevia Mahdaliza Idrus \& Mojgan Kouhnavard, MICRORING RESONATOR FOR SECURED OPTICAL COMMUNICATION. USA: Amazon, 2014.

[26] C. Tanaram, C. Teeka, R. Jomtarak, P. P. Yupapin, M. A. Jalil, I. S. Amiri \& J. Ali, (2011) "ASK-to-PSK generation based on nonlinear microring resonators coupled to one MZI arm", Procedia Engineering, 8 432-435.

[27] IS Amiri, MRK Soltanian \& H Ahmad, bright soliton array (BSA) for optical communication using the wired/wireless link, in Optical Communication Systems: Fundamentals, Techniques and Applications, ed New York: Novascience Publisher, 2015.

[28] I. S. Amiri, S. Babakhani, G. Vahedi, J. Ali \& P. Yupapin, (2012) "Dark-Bright Solitons Conversion System for Secured and Long Distance Optical Communication", IOSR Journal of Applied Physics (IOSR-JAP), 2(1), 43-48.

[29] S. E. Alavi, I. S. Amiri, S. M. Idrus \& A. S. M. Supa'at, (2014) "Generation and Wired/Wireless Transmission of IEEE802.16m Signal Using Solitons Generated By Microring Resonator", Optical and Quantum Electronics,

[30] I. S. Amiri, A. Nikoukar, G. Vahedi, A. Shojaei, J. Ali \& P. Yupapin, (2012) "Frequency-Wavelength Trapping by Integrated Ring Resonators For Secured Network and Communication Systems", International Journal of Engineering Research and Technology (IJERT), 1(5),

[31] I. S. Amiri, A. Nikoukar, A. Shahidinejad, J. Ali \& P. Yupapin, (2012), "Generation of discrete frequency and wavelength for secured computer networks system using integrated ring resonators", in Computer and Communication Engineering (ICCCE) Conference, Malaysia, 775-778.

[32] J. Ali, M. Kouhnavard, I. S. Amiri, A. Afroozeh, M. A. Jalil, I. Naim \& P. P. Yupapin, (2010) "Localization of soliton pulse using nano-waveguide", presented at the ICAMN, International Conference, Prince Hotel, Kuala Lumpur, Malaysia.

[33] Abdolkarim Afroozeh, Iraj Sadegh Amiri \& Alireza Zeinalinezhad, Micro Ring Resonators and Applications. Saarbrücken, Germany: LAP LAMBERT Academic Publishing, 2014.

[34] I. S. Amiri, S. Ghorbani, P. Naraei \& H. Ahmad, (2015) "Chaotic Carrier Signal Generation and Quantum Transmission Along Fiber Optics Communication Using Integrated Ring Resonators", Quantum Matter, 4(2),

[35] I. S. Amiri \& J. Ali, (2013) "Data Signal Processing Via a Manchester Coding-Decoding Method Using Chaotic Signals Generated by a PANDA Ring Resonator", Chinese Optics
Letters, 11(4), 041901(4).

[36] I. S. Amiri, K. Raman, A. Afroozeh, M. A. Jalil, I. N. Nawi, J. Ali \& P. P. Yupapin, (2011) "Generation of DSA for security application", Procedia Engineering, 8 360-365.

[37] I. S. Amiri, S. E. Alavi, M. Bahadoran, A. Afroozeh \& H. Ahmad, (2015) "Nanometer Bandwidth Soliton Generation and Experimental Transmission within Nonlinear Fiber Optics Using an Add-Drop Filter System", Journal of Computational and Theoretical Nanoscience (CTN), 12(2),

[38] J. Ali, I. S. Amiri, M. Jalil, M. Kouhnavard, A. Afroozeh, I. Naim \& P. Yupapin, (2010) "Narrow UV pulse generation using MRR and NRR system", presented at the ICAMN, International Conference, Prince Hotel, Kuala Lumpur, Malaysia

[39] I. S. Amiri, S. Soltanmohammadi, A. Shahidinejad \& j. Ali, (2013) "Optical quantum transmitter with finesse of 30 at 800$\mathrm{nm}$ central wavelength using microring resonators", Optical and Quantum Electronics, 45(10), 1095-1105.

[40] M. Kouhnavard, I. S. Amiri, M. Jalil, A. Afroozeh, J. Ali \& P. P. Yupapin, (2010) "QKD via a quantum wavelength router using spatial soliton", AIP Conference Proceedings, 1347 210216.

[41] I. S. Amiri \& A. Nikoukar, (2010-2011) "Quantum Information Generation Using Optical Potential Well", presented at the Network Technologies \& Communications (NTC) Conference, Singapore.

[42] I. S. Amiri, S. E. Alavi \& S. M. Idrus, Results of Digital Soliton Pulse Generation and Transmission Using Microring Resonators, in Soliton Coding for Secured Optical Communication Link, ed USA: Springer, 2015, pp. 41-56.

[43] I. S. Amiri \& A. Nikoukar, (2010-2011) "Secured Binary Codes Generation for Computer Network Communication", presented at the Network Technologies \& Communications (NTC) Conference, Singapore.

[44] I. S. Amiri, H. Ahmad \& P. Naraei, (2015) "Optical Transmission Characteristics of an Optical Add-Drop Interferometer System", Quantum Matter, 4(5),

[45] A. Afroozeh, I. S. Amiri, M. Bahadoran, J. Ali \& P. P. Yupapin, (2012) "Simulation of Soliton Amplification in Micro Ring Resonator for Optical Communication", Jurnal Teknologi (Sciences and Engineering), 55 271-277.

[46] Iraj Sadegh Amiri, Ali Nikoukar \& Sayed Ehsan Alavi, Soliton and Radio over Fiber (RoF) Applications. Saarbrücken, Germany: LAP LAMBERT Academic Publishing, 2014.

[47] I. S. Amiri, S. E. Alavi \& S. M. Idrus', (2014) "Solitonic Pulse Generation and Characterization by Integrated Ring Resonators", presented at the 5th International Conference on Photonics 2014 (ICP2014), Kuala Lumpur.

[48] J. Ali, K. Raman, M. Kouhnavard, I. S. Amiri, M. A. Jalil, A. Afroozeh \& P. P. Yupapin, (2011) "Dark soliton array for communication security", presented at the AMN-APLOC International Conference, Wuhan, China.

[49] J. Ali, M. A. Jalil, I. S. Amiri \& P. P. Yupapin, (2010) "Darkbright solitons conversion system via an add/drop filter for signal security application", presented at the ICEM, Legend Hotel, Kuala Lumpur, Malaysia. 
[50] J. Ali, M. A. Jalil, I. S. Amiri, A. Afroozeh, M. Kouhnavard \& P. P. Yupapin, (2010) "Generation of tunable dynamic tweezers using dark-bright collision", presented at the ICAMN, International Conference, Prince Hotel, Kuala Lumpur, Malaysia

[51] IS Amiri \& A Afroozeh, Introduction of Soliton Generation, in Ring Resonator Systems to Perform Optical Communication Enhancement Using Soliton, ed USA: Springer, 2014.

[52] A. Nikoukar, I. S. Amiri, A. Shahidinejad, A. Shojaei, J. Ali \& P. Yupapin, (2012), "MRR quantum dense coding for optical wireless communication system using decimal convertor", in Computer and Communication Engineering (ICCCE) Conference, Malaysia, 770-774.

[53] J. Ali, M. Kouhnavard, I. S. Amiri, M. A. Jalil, A. Afroozeh \& P. P. Yupapin (2010) "Security confirmation using temporal dark and bright soliton via nonlinear system", presented at the ICAMN, International Conference, Prince Hotel, Kuala Lumpur, Malaysia

[54] I. S. Amiri \& J. Ali, (2014) "Deform of Biological Human Tissue Using Inserted Force Applied by Optical Tweezers Generated By PANDA Ring Resonator", Quantum Matter, $3(1), 24-28$.

[55] S. E. Alavi, I. S. Amiri, M. R. K. Soltanian, A.S.M. Supa'at, N. Fisal \& H. Ahmad, (2015) "Generation of Femtosecond Soliton Tweezers Using a Half-Panda System for Modeling the Trapping of a Human Red Blood Cell", Journal of Computational and Theoretical Nanoscience (CTN), 12(1),

[56] I. S. Amiri \& J. Ali, (2012) "Generation of Nano Optical Tweezers Using an Add/drop Interferometer System", presented at the 2nd Postgraduate Student Conference (PGSC), Singapore.

[57] A. Nikoukar, I. S. Amiri \& J. Ali, (2013) "Generation of Nanometer Optical Tweezers Used for Optical Communication Networks", International Journal of Innovative Research in Computer and Communication Engineering, 1(1), 77-85.

[58] I. Sadegh Amiri, M. Nikmaram, A. Shahidinejad \& J. Ali, (2013) "Generation of potential wells used for quantum codes transmission via a TDMA network communication system", Security and Communication Networks, 6(11), 1301-1309.

[59] I. S. Amiri, A. Nikoukar, A. Shahidinejad, M. Ranjbar, J. Ali \& P. P. Yupapin, (2012) "Generation of Quantum Photon Information Using Extremely Narrow Optical Tweezers for Computer Network Communication", GSTF Journal on Computing (joc), 2(1), 140.

[60] I. S. Amiri \& J. Ali, (2013) "Nano Particle Trapping By Ultra-short tweezer and wells Using MRR Interferometer System for Spectroscopy Application", Nanoscience and Nanotechnology Letters, 5(8), 850-856.

[61] I. S. Amiri \& J. Ali, (2013) "Nano Optical Tweezers Generation Used for Heat Surgery of a Human Tissue Cancer Cells Using Add/Drop Interferometer System", Quantum Matter, 2(6), 489-493.

[62] I. S. Amiri \& J. Ali, (2013) "Optical Buffer Application Used for Tissue Surgery Using Direct Interaction of Nano Optical Tweezers with Nano Cells", Quantum Matter, 2(6), 484-488.

[63] S. E. Alavi, I. S. Amiri, H. Ahmad, N. Fisal \& ASM. Supa'at, (2015) "Optical Amplification of Tweezers and Bright Soliton
Using an Interferometer Ring Resonator System", Journal of Computational and Theoretical Nanoscience (CTN), 12(4),

[64] I. S. Amiri, B. Barati, P. Sanati, A. Hosseinnia, HR Mansouri Khosravi, S. Pourmehdi, A. Emami \& J. Ali, (2014) "Optical Stretcher of Biological Cells Using Sub-Nanometer Optical Tweezers Generated by an Add/Drop Microring Resonator System", Nanoscience and Nanotechnology Letters, 6(2), 111-117.

[65] I. S. Amiri, A. Nikoukar, A Shahidinejad, T. Anwar \& J. Ali, (2014) "Quantum Transmission of Optical Tweezers Via Fiber Optic Using Half-Panda System", Life Science Journal, 10(12s), 391-400.

[66] J. Ali, I. S. Amiri, A. Afroozeh, M. Kouhnavard, M. Jalil \& P. Yupapin, (2010) "Simultaneous dark and bright soliton trapping using nonlinear MRR and NRR", presented at the ICAMN, International Conference, Prince Hotel, Kuala Lumpur, Malaysia

[67] I. S. Amiri, M. A. Jalil, F. K. Mohamad, N. J. Ridha, J. Ali \& P P. Yupapin, (2010) "Storage of Atom/Molecules/Photon using Optical Potential Wells", presented at the International Conference on Experimental Mechanics (ICEM), Kuala Lumpur, Malaysia.

[68] I. S. Amiri, A. Shahidinejad, A. Nikoukar, J. Ali \& P. Yupapin, (2012) "A Study oF Dynamic Optical Tweezers Generation For Communication Networks", International Journal of Advances in Engineering \& Technology (IJAET), 4(2), 38-45

[69] N. Suwanpayak, S. Songmuang, M. A. Jalil, I. S. Amiri, I. Naim, J. Ali \& P. P. Yupapin, (2010) "Tunable and storage potential wells using microring resonator system for bio-cell trapping and delivery", AIP Conference Proceedings, 1341 289-291.

[70] Iraj Sadegh Amiri \& Abdolkarim Afroozeh, Ring Resonator Systems to Perform the Optical Communication Enhancement Using Soliton. USA: Springer, 2014.

[71] I. S. Amiri \& J. Ali, (2013) "Single and Multi Optical Soliton Light Trapping and Switching Using Microring Resonator", Quantum Matter, 2(2), 116-121.

[72] A. A. Shojaei \& I. S. Amiri, (2011) "Soliton for Radio wave generation", presented at the International Conference for Nanomaterials Synthesis and Characterization (INSC), Kuala Lumpur, Malaysia.

[73] J. Ali, A. Mohamad, I. Nawi, I. S. Amiri, M. Jalil, A. Afroozeh \& P. Yupapin, (2010) "Stopping a dark soliton pulse within an NNRR", presented at the AMN-APLOC International Conference, Wuhan, China

[74] I. S. Amiri, G. Vahedi, A. Shojaei, A. Nikoukar, J. Ali \& P. P. Yupapin, (2012) "Secured Transportation of Quantum Codes Using Integrated PANDA-Add/drop and TDMA Systems", International Journal of Engineering Research and Technology (IJERT), 1(5),

[75] M. Kouhnavard, A. Afroozeh, M. A. Jalil, I. S. Amiri, J. Ali \& P. P. Yupapin, (2010), "Soliton Signals and the Effect of Coupling Coefficient in MRR Systems", in Faculty of Science Postgraduate Conference (FSPGC), Universiti Teknologi Malaysia.

[76] I. S. Amiri, D. Gifany \& J. Ali, (2013) "Ultra-short Multi Soliton Generation for Application in Long Distance Communication", Journal of Basic and Applied Scientific Research (JBASR), 3(3), 442-451. 
[77] I. S. Amiri, A. Afroozeh, M. Bahadoran, J. Ali \& P. P. Yupapin, (2011) "Up and Down Link of Soliton for Network Communication", presented at the National Science Postgraduate Conference, NSPC, Universiti Teknologi Malaysia.

[78] S. E. Alavi, I. S. Amiri, M. Khalily, A. S. M. Supa' at, N. Fisal, H. Ahmad \& S. M. Idrus, (2014) "W-Band OFDM for Radioover-Fibre Direct-Detection Link Enabled By Frequency Nonupling Optical Up-Conversion", IEEE Photonics Journal $6(6)$,

[79] A. Afroozeh, I. S. Amiri, M. A. Jalil, M. Kouhnavard, J. Ali \& P. P. Yupapin, (2011) "Multi Soliton Generation for Enhance Optical Communication", Applied Mechanics and Materials, 83 136-140.

[80] I. S. Amiri, (2011), "Optical Soliton Trapping for Quantum Key Generation", in The International Conference for Nano materials Synthesis and Characterization, Malaysia.

[81] IS Amiri \& A Afroozeh, Soliton Generation Based Optical Communication, in Ring Resonator Systems to Perform Optical Communication Enhancement Using Soliton, ed USA: Springer, 2014.

[82] I. S. Amiri, S. E. Alavi, S. M. Idrus, A. S. M. Supa'at, J. Ali \& P. P. Yupapin, (2014) "W-Band OFDM Transmission for Radio-over-Fiber link Using Solitonic Millimeter Wave Generated by MRR", IEEE Journal of Quantum Electronics, 50(8), $622-628$.

[83] J. Ali, A. Afroozeh, I. S. Amiri, M. Jalil \& P. Yupapin, (2010) "Wide and narrow signal generation using chaotic wave", presented at the Nanotech Malaysia, International Conference on Enabling Science \& Technology, Kuala Lumpur, Malaysia.

[84] Y. S. Neo, S. M. Idrus, M. F. Rahmat, S. E. Alavi \& I. S. Amiri', (2014) "Adaptive Control for Laser Transmitter Feedforward Linearization System", IEEE Photonics Journal $6(4)$

[85] I. S. Amiri, A. Nikoukar \& J. Ali, (2013) "GHz Frequency Band Soliton Generation Using Integrated Ring Resonator for WiMAX Optical Communication", Optical and Quantum Electronics, 46(9), 1165-1177.

[86] I. S. Amiri, S. E. Alavi, H. Ahmad, A.S.M. Supa'at \& N. Fisal, (2014) "Numerical Computation of Solitonic Pulse Generation for Terabit/Sec Data Transmission", Optical and Quantum Electronics,

[87] I. S. Amiri \& J. Ali, (2014) "Optical Quantum Generation and Transmission of 57-61 GHz Frequency Band Using an Optical Fiber Optics ", Journal of Computational and Theoretical Nanoscience (CTN), 11(10), 2130-2135.

[88] I. S. Amiri, S. E. Alavi \& S. M. Idrus, Theoretical Background of Microring Resonator Systems and Soliton Communication, in Soliton Coding for Secured Optical Communication Link, ed USA: Springer, 2015, pp. 17-39.

[89] I. S. Amiri, M. Ebrahimi, A. H. Yazdavar, S. Gorbani, S. E. Alavi, Sevia M. Idrus \& J. Ali, (2014) "Transmission of data with orthogonal frequency division multiplexing technique for communication networks using $\mathrm{GHz}$ frequency band soliton carrier", IET Communications, 8(8), 1364 - 1373.

[90] I. S. Amiri, A. Shahidinejad, A. Nikoukar, M. Ranjbar, J. Ali \& P. P. Yupapin, (2012) "Digital Binary Codes Transmission via TDMA Networks Communication System Using Dark and
Bright Optical Soliton", GSTF Journal on Computing (joc), 2(1), 12.

[91] A. A. Shojaei \& I. S. Amiri, (2011) "DSA for Secured Optical Communication", presented at the International Conference for Nanomaterials Synthesis and Characterization (INSC), Kuala Lumpur, Malaysia.

[92] I. S. Amiri, D. Gifany \& J. Ali, (2013) "Long Distance Communication Using Localized Optical Soliton Via Entangled Photon", IOSR Journal of Applied Physics (IOSRJAP), 3(1), 32-39.

[93] I. S. Amiri, P. Naraei \& J. Ali, (2014) "Review and Theory of Optical Soliton Generation Used to Improve the Security and High Capacity of MRR and NRR Passive Systems", Journal of Computational and Theoretical Nanoscience (CTN), 11(9) 1875-1886.

[94] IS Amiri, MZ Zulkifli \& H Ahmad, (2014) "Soliton comb generation using add-drop ring resonators", International Research Journal of Telecommunications and Information Technology, 1(1), 002-008.

[95] S. E. Alavi, I.S.Amiri, A. S. M. Supa'at \& S. M. Idrus, (2015) "Indoor Data Transmission Over Ubiquitous Infrastructure of Powerline Cables and LED Lighting", Journal of Computational and Theoretical Nanoscience (CTN), 12(4),

[96] A. Shahidinejad, A. Nikoukar, I. S. Amiri, M. Ranjbar, A. Shojaei, J. Ali \& P. Yupapin, (2012), "Network system engineering by controlling the chaotic signals using silicon micro ring resonator", in Computer and Communication Engineering (ICCCE) Conference, Malaysia, 765-769.

[97] I. S. Amiri, S. E. Alavi \& H. Ahmad, (2015) "RF signal generation and wireless transmission using PANDA and Add/drop systems", Journal of Computational and Theoretical Nanoscience (CTN),

[98] M. A. Jalil, I. S. Amiri, C. Teeka, J. Ali \& P. P. Yupapin, (2011) "All-optical Logic XOR/XNOR Gate Operation using Microring and Nanoring Resonators", Global Journal of Physics Express, 1(1), 15-22.

[99] C. Teeka, S. Songmuang, R. Jomtarak, P. Yupapin, M. Jalil, I. S. Amiri \& J. Ali, (2011) "ASK-to-PSK Generation based on Nonlinear Microring Resonators Coupled to One MZI Arm", AIP Conference Proceedings, 1341(1), 221-223.

[100] I. S. Amiri, S. E. Alavi \& S. M. Idrus, Introduction of Fiber Waveguide and Soliton Signals Used to Enhance the Communication Security, in Soliton Coding for Secured Optical Communication Link, ed USA: Springer, 2015, pp. 116.

[101] I. S. Amiri \& H. Ahmad, (2015) "Multiplex and De-multiplex of Generated Multi Optical Soliton By MRRs Using Fiber Optics Transmission Link", Quantum Matter, 4(4),

[102] I. S. Amiri \& J. Ali, (2014) "Generating Highly Dark-Bright Solitons by Gaussian Beam Propagation in a PANDA Ring Resonator", Journal of Computational and Theoretical Nanoscience (CTN), 11(4), 1092-1099.

[103] J. Ali, A. Afroozeh, I. S. Amiri, M. A. Jalil, M. Kouhnavard \& P. P. Yupapin, (2010) "Generation of continuous optical spectrum by soliton into a nano-waveguide", presented at the ICAMN, International Conference, Prince Hotel, Kuala Lumpur, Malaysia 
[104] IS Amiri \& A Afroozeh, Mathematics of Soliton Transmission in Optical Fiber, in Ring Resonator Systems to Perform Optical Communication Enhancement Using Soliton, ed USA: Springer, 2014.

[105] A. Afroozeh, I. S. Amiri, A. Zeinalinezhad, S. E. Pourmand \& H. Ahmad, (2015) "Comparison of Control Light using Kramers-Kronig Method by Three Waveguides", Journal of Computational and Theoretical Nanoscience (CTN),

[106] I. S. Amiri, M. A. Jalil, A. Afroozeh, M. Kouhnavard , J. Ali \& P. P. Yupapin, (2010), "Controlling Center Wavelength and Free Spectrum Range by MRR Radii", in Faculty of Science Postgraduate Conference (FSPGC), Universiti Teknologi Malaysia.

[107] J. Ali, A. Afroozeh, I. S. Amiri, M. A. Jalil \& P. P. Yupapin, (2010) "Dark and Bright Soliton trapping using NMRR", presented at the ICEM, Legend Hotel, Kuala Lumpur, Malaysia.

[108] M. A. Jalil, I. S. Amiri, M. Kouhnavard, A. Afroozeh, J. Ali \& P. P. Yupapin, (2010), "Finesse Improvements of Light Pulses within MRR System", in Faculty of Science Postgraduate Conference (FSPGC), Universiti Teknologi Malaysia.

[109] I. S. Amiri, A. Afroozeh, J. Ali \& P. P. Yupapin, (2012) "Generation Of Quantum Codes Using Up And Down Link Optical Solition", Jurnal Teknologi (Sciences and Engineering), 55 97-106.

[110] J. Ali, I. S. Amiri, M. A. Jalil, A. Afroozeh, M. Kouhnavard \& P. Yupapin, (2010) "Novel system of fast and slow light generation using micro and nano ring resonators", presented at the ICAMN, International Conference, Prince Hotel, Kuala Lumpur, Malaysia

[111] IS Amiri, SE Alavi, A Shahidinejad, A Nikoukar, T Anwar, ASM Supa'at, SM Idrus \& N. K. Yen, (2014) "Characterization of Ultra-Short Soliton Generation Using MRRs", presented at the The 2014 Third ICT International Student Project Conference (ICT-ISPC2014), Thailand

[112] N. J. Ridha, F. K. Mohamad, I. S. Amiri, Saktioto, J. Ali \& P. P. Yupapin, (2010) "Controlling Center Wavelength and Free Spectrum Range by MRR Radii", presented at the International Conference on Experimental Mechanics (ICEM), Kuala Lumpur, Malaysia.

[113] I. S. Amiri \& J. Ali, (2013) "Controlling Nonlinear Behavior of a SMRR for Network System Engineering", International Journal of Engineering Research and Technology (IJERT), 2(2),

[114] A. Afroozeh, I. S. Amiri, J. Ali \& P. P. Yupapin, (2012) "Determination Of Fwhm For Solition Trapping", Jurnal Teknologi (Sciences and Engineering), 55 77-83.

[115] IS Amiri, H. Ahmad \& Hamza M. R. Al-Khafaji, (2015) "Full width at half maximum (FWHM) analysis of solitonic pulse applicable in optical network communication", American Journal of Networks and Communications, 4(2-1), 1-5.

[116] J. Ali, M. Jalil, I. S. Amiri, A. Afroozeh, M. Kouhnavard, I. Naim \& P. Yupapin, (2010) "Multi-wavelength narrow pulse generation using MRR", presented at the ICAMN, International Conference, Prince Hotel, Kuala Lumpur, Malaysia

[117] I. S. Amiri, M. Nikmaram, A. Shahidinejad \& J. Ali, (2012) "Cryptography Scheme of an Optical Switching System Using
Pico/Femto Second Soliton Pulse", International Journal of Advances in Engineering \& Technology (IJAET), 5(1), 176184.

[118] A. Afroozeh, M. Kouhnavard, I. S. Amiri, M. A. Jalil, J. Ali \& P. P. Yupapin, (2010), "Effect of Center Wavelength on MRR Performance", in Faculty of Science Postgraduate Conference $(F S P G C)$, Universiti Teknologi Malaysia.

[119] S. Saktioto, S. Daud, M. A. Jalil, I. S. Amiri \& P. P. Yupapin, (2010) "FBG sensing system for outdoor temperature measurement", presented at the ICEM, Legend Hotel, Kuala Lumpur, Malaysia.

[120] M. Kouhnavard, A. Afroozeh, I. S. Amiri, M. A. Jalil, J. Ali \& P. P. Yupapin, (2010) "New system of Chaotic Signal Generation Using MRR", presented at the International Conference on Experimental Mechanics (ICEM), Kuala Lumpur, Malaysia.

[121] Iraj Sadegh Amiri, Falah Jabar Rahim, Ari Sabir Arif, Sogand Ghorbani, Parisa Naraei, David Forsyth \& Jalil Ali, (2014) "Single Soliton Bandwidth Generation and Manipulation by Microring Resonator", Life Science Journal, 10(12s), 904-910.

[122] I. S. Amiri, A. Afroozeh, I. N. Nawi, M. A. Jalil, A. Mohamad, J. Ali \& P. P. Yupapin, (2011) "Dark Soliton Array for communication security", Procedia Engineering, 8 417-422.

[123] I. S. Amiri, D. Gifany \& J. Ali, (2013) "Entangled Photon Encoding Using Trapping of Picoseconds Soliton pulse", IOSR Journal of Applied Physics (IOSR-JAP), 3(1), 25-31.

[124] S. E. Alavi, I. S. Amiri, S. M. Idrus \& J. Ali, (2013) "Optical Wired/Wireless Communication Using Soliton Optical Tweezers", Life Science Journal, 10(12s), 179-187.

[125] I. S. Amiri, G. Vahedi, A. Nikoukar, A. Shojaei, J. Ali \& P. Yupapin, (2012) "Decimal Convertor Application for Optical Wireless Communication by Generating of Dark and Bright Signals of soliton", International Journal of Engineering Research and Technology (IJERT), 1(5),

[126] I. S. Amiri, A. Afroozeh, M. Bahadoran, J. Ali \& P. P. Yupapin, (2012) "Molecular Transporter System for Qubits Generation", Jurnal Teknologi (Sciences and Engineering), 55 155-165.

[127] A. Afroozeh, I. S. Amiri, M. Kouhnavard, M. Jalil, J. Ali \& P. Yupapin, (2010) "Optical dark and bright soliton generation and amplification", AIP Conference Proceedings, 1341 259263.

[128] A. Afroozeh, A. Zeinalinezhad, SE. Pourmand \& IS. Amiri, (2014) "Determination of Suitable Material to Control of Light", International Journal of Biology, Pharmacy and Allied Sciences (IJBPAS), 3(11), 2410-2421.

[129] S. Saktioto, S. Daud, J. Ali, M. A. Jalil, I. S. Amiri \& P. P. Yupapin, (2010) "FBG simulation and experimental temperature measurement", presented at the ICEM, Legend Hotel, Kuala Lumpur, Malaysia.

[130] I. S. Amiri \& J. Ali, (2014) "Picosecond Soliton pulse Generation Using a PANDA System for Solar Cells Fabrication", Journal of Computational and Theoretical Nanoscience (CTN), 11(3), 693-701.

[131] J. Ali, M. A. Jalil, I. S. Amiri \& P. P. Yupapin, (2010) "Effects of MRR parameter on the bifurcation behavior", presented at the Nanotech Malaysia, International Conference on Enabling Science \& Technology KLCC, Kuala Lumpur, Malaysia 
[132] A. Afroozeh, M. Bahadoran, I. S. Amiri, A. R. Samavati, J. Ali \& P. P. Yupapin, (2011) "Fast Light Generation Using Microring Resonators for Optical Communication", presented at the National Science Postgraduate Conference, NSPC, Universiti Teknologi Malaysia.

[133] P. P. Yupapin, M. A. Jalil, I. S. Amiri, I. Naim \& J. Ali, (2010) "New Communication Bands Generated by Using a Soliton Pulse within a Resonator System", Circuits and Systems, 1(2), 71-75.

[134] I. S. Amiri, A. Nikoukar, A. Shahidinejad \& Toni Anwar, (2014) "The Proposal of High Capacity GHz Soliton Carrier Signals Applied for Wireless Commutation", Reviews in Theoretical Science, 2(4), 320-333.

[135] A. Afroozeh, A.Zeinalinezhad, I. S. Amiri \& S. E. Pourmand, (2014) "Stop Light Generation using Nano Ring Resonators for ROM", Journal of Computational and Theoretical Nanoscience (CTN), 12(3),

[136] J. Ali, I. S. Amiri, M. A. Jalil, M. Hamdi, F. K. Mohamad, N. J. Ridha \& P. P. Yupapin, (2010) "Trapping spatial and temporal soliton system for entangled photon encoding", presented at the Nanotech Malaysia, International Conference on Enabling Science \& Technology, Kuala Lumpur, Malaysia.

[137] Ali Shahidinejad, Iraj Sadegh Amiri \& Toni Anwar, (2014) "Enhancement of Indoor Wavelength Division MultiplexingBased Optical Wireless Communication Using Microring Resonator", Reviews in Theoretical Science, 2(3), 201-210.

[138] I. S. Amiri, A. Nikoukar \& J. Ali, (2013) "Nonlinear Chaotic Signals Generation and Transmission Within an Optical Fiber Communication Link", IOSR Journal of Applied Physics (IOSR-JAP), 3(1), 52-57.

[139] J. Ali, A. Afroozeh, I. S. Amiri, M. Hamdi, M. Jalil, M. Kouhnavard \& P. Yupapin, (2010) "Entangled photon generation and recovery via MRR", presented at the ICAMN, International Conference, Prince Hotel, Kuala Lumpur, Malaysia.

[140] J. Ali, I. S. Amiri, M. A. Jalil, A. Afroozeh, M. Kouhnavard \& P. P. Yupapin, (2010) "Multi-soliton generation and storage for nano optical network using nano ring resonators", presented at the ICAMN, International Conference, Prince Hotel, Kuala Lumpur, Malaysia

[141] A. Afroozeh, I. S. Amiri, M. Kouhnavard, M. Bahadoran, M. A. Jalil, J. Ali \& P. P. Yupapin, (2010) "Optical Memory Time using Multi Bright Soliton", presented at the International Conference on Experimental Mechanics (ICEM), Kuala Lumpur, Malaysia.

[142] M. Imran, R. A. Rahman \& I. S. Amiri, (2010), "Fabrication of Diffractive Optical Element using Direct Writing CO2 Laser Irradiation", in Faculty of Science Postgraduate Conference ( $F S P G C)$, Universiti Teknologi Malaysia.

[143] J. Ali, M. A. Jalil, I. S. Amiri \& P. P. Yupapin, (2010) "MRR quantum dense coding", presented at the Nanotech Malaysia, International Conference on Enabling Science \& Technology, KLCC, Kuala Lumpur, Malaysia

[144] I. S. Amiri, A. Nikoukar \& J. Ali, (2013) "New System of chaotic signal generation based on coupling coefficients applied to an Add/Drop System", International Journal of Advances in Engineering \& Technology (IJAET), 6(1), 78-87.

[145] A. Afroozeh, M. Bahadoran, I. S. Amiri, A. R. Samavati, J. Ali
\& P. P. Yupapin, (2012) "Fast Light Generation Using GaAlAs/GaAs Waveguide", Jurnal Teknologi (Sciences and Engineering), 57 17-23.

[146] J. Ali, H. Nur, S. Lee, A. Afroozeh, I. S. Amiri, M. Jalil, A. Mohamad \& P. Yupapin, (2010) "Short and millimeter optical soliton generation using dark and bright soliton", presented at the AMN-APLOC International Conference, Wuhan, China.

[147] I. S. Amiri \& J. Ali, (2014) "Femtosecond Optical Quantum Memory generation Using Optical Bright Soliton", Journal of Computational and Theoretical Nanoscience (CTN), 11(6), 1480-1485.

[148] I. S. Amiri, A. Afroozeh \& M. Bahadoran, (2011) "Simulation and Analysis of Multisoliton Generation Using a PANDA Ring Resonator System", Chinese Physics Letters, 28(10), 104205 .

[149] I. S. Amiri \& A. Afroozeh, Spatial and Temporal Soliton Pulse Generation By Transmission of Chaotic Signals Using Fiber Optic Link in Advances in Laser and Optics Research. vol. 11, ed New York: Nova Science Publisher, 2015.

[150] I. S. Amiri, H. Ahmad \& A. Shahidinejad, (2015) "Generating of 57-61 GHz Frequency Band Using a Panda Ring Resonator", Quantum Matter, 4(4),

[151] J. Ali, M. Kouhnavard, A. Afroozeh, I. S. Amiri, M. A. Jalil \& P. P. Yupapin, (2010) "Optical bistability in a FORR", presented at the ICEM, Legend Hotel, Kuala Lumpur, Malaysia.

[152] IS Amiri, SE Alavi, MRK Soltanian \& H Ahmad, (2015) "Tunable Channel Spacing of Soliton Comb Generation Using Add-drop Microring Resonators (MRRs)", Journal of Computational and Theoretical Nanoscience (CTN),

[153] A. Afrozeh, A. Zeinalinezhad, S. E. Pourmand \& I. S. Amiri, (2014) "Attosecond Pulse Generation Using Nano Ring Waveguides", INTERNATIONAL JOURNAL OF CURRENT LIFE SCIENCES, 4(9), 7573-7575.

[154] I. S. Amiri, Light Detection and Ranging Using NIR $(810 \mathrm{~nm})$ Laser Source. Germany: LAP LAMBERT Academic Publishing, 2014.

[155] J. Ali, A. Afroozeh, M. Hamdi, I. S. Amiri, M. A. Jalil, M. Kouhnavard \& P. Yupapin, (2010) "Optical bistability behaviour in a double-coupler ring resonator", presented at the ICAMN, International Conference, Prince Hotel, Kuala Lumpur, Malaysia

[156] S. E. Alavi, I. S. Amiri, S. M. Idrus, ASM. Supa'at \& J. Ali, (2013) "Chaotic Signal Generation and Trapping Using an Optical Transmission Link", Life Science Journal, 10(9s), 186-192.

[157] Iraj Sadegh Amiri, Sayed Ehsan Alavi \& Sevia Mahdaliza Idrus, Soliton Coding for Secured Optical Communication Link. USA: Springer, 2014.

[158] J. Ali, S. Saktioto, M. Hamdi \& I. S. Amiri, (2010) "Dynamic silicon dioxide fiber coupling polarized by voltage breakdown", presented at the Nanotech Malaysia, International Conference on Enabling Science \& Technology, KLCC, Kuala Lumpur, Malaysia.

[159] I. S. Amiri \& J. Ali, (2014) "Simulation of the Single Ring Resonator Based on the Z-transform Method Theory", Quantum Matter, 3(6), 519-522. 
[160] F. K. Mohamad, N. J. Ridha, I. S. Amiri, J. A. Saktioto \& P. P. Yupapin, (2010) "Effect of Center Wavelength on MRR Performance", presented at the International Conference on Experimental Mechanics (ICEM), Kuala Lumpur, Malaysia.

[161] N. J. Ridha, F. K. Mohamad, I. S. Amiri, Saktioto, J. Ali \& P. P Yupapin, (2010) "Soliton Signals and The Effect of Coupling Coefficient in MRR Systems", presented at the International Conference on Experimental Mechanics (ICEM), Kuala Lumpur, Malaysia.

[162] J. Ali, K. Kulsirirat, W. Techithdeera, M. A. Jalil, I. S. Amiri, I. Naim \& P. P. Yupapin, (2010) "Temporal dark soliton behavior within multi-ring resonators", presented at the Nanotech Malaysia, International Conference on Enabling Science \& Technology, Malaysia

[163] P. Sanati, A. Afroozeh, I. S. Amiri, J.Ali \& Lee Suan Chua, (2014) "Femtosecond Pulse Generation using Microring Resonators for Eye Nano Surgery", Nanoscience and Nanotechnology Letters, 6(3), 221-226

[164] I. S. Amiri, M. A. Jalil, F. K. Mohamad, N. J. Ridha, J. Ali \& P. P. Yupapin, (2010) "Storage of Optical Soliton Wavelengths Using NMRR", presented at the International Conference on Experimental Mechanics (ICEM), Kuala Lumpur, Malaysia.

[165] F. K. Mohamad, N. J. Ridha, I. S. Amiri, J. A. Saktioto \& P. P. Yupapin, (2010) "Finesse Improvements of Light Pulses within MRR System", presented at the International Conference on Experimental Mechanics (ICEM), Kuala Lumpur, Malaysia.

[166] Iraj Sadegh Amiri, Sayed Ehsan Alavi, S. M. Idrus, Abdolkarim Afroozeh \& Jalil Ali, Soliton Generation by Ring Resonator for Optical Communication Application. New York: Novascience Publishers, 2014.

[167] A. Shahidinejad, S. Soltanmohammadi, I. S. Amiri \& T. Anwar, (2014) "Solitonic Pulse Generation for Inter-Satellite Optical Wireless Communication", Quantum Matter, 3(2), $150-154$.
[168] S. Saktioto, M. Hamdi, I. S. Amiri \& J. Ali, (2010) "Transition of diatomic molecular oscillator process in $\mathrm{THz}$ region", presented at the International Conference on Experimental Mechanics (ICEM), Legend Hotel, Kuala Lumpur, Malaysia.

[169] I. S. Amiri, M. Ranjbar, A. Nikoukar, A. Shahidinejad, J. Ali \& P. Yupapin, (2012), "Multi optical Soliton generated by PANDA ring resonator for secure network communication", in Computer and Communication Engineering (ICCCE) Conference, Malaysia, 760-764.

[170] J. Ali, M. Aziz, I. S. Amiri, M. Jalil, A. Afroozeh, I. Nawi \& P. Yupapin, (2010) "Soliton wavelength division in MRR and NRR Systems", presented at the AMN-APLOC International Conference, Wuhan, China

[171] J. Ali, I. S. Amiri, M. A. Jalil, M. Hamdi, F. K. Mohamad, N. J. Ridha \& P. P. Yupapin, (2010) "Proposed molecule transporter system for qubits generation", presented at the Nanotech Malaysia, International Conference on Enabling Science \& Technology, Malaysia

[172] A Nikoukar, IS Amiri, SE Alavi, A Shahidinejad, T Anwar, ASM Supa'at, SM Idrus \& L. Y. Teng', (2014) "Theoretical and Simulation Analysis of The Add/Drop Filter Ring Resonator Based on the Z-transform Method Theory", presented at the The 2014 Third ICT International Student Project Conference (ICT-ISPC2014), Thailand.

[173] I. S. Amiri, M. H. Khanmirzaei, M. Kouhnavard, P. P. Yupapin \& J. Ali, Quantum Entanglement using Multi Dark Soliton Correlation for Multivariable Quantum Router, in Quantum Entanglement A. M. Moran, Ed., ed New York: Nova Science Publisher, 2012, pp. 111-122.

[174] A. Afroozeh, I. S. Amiri, A. Samavati, J. Ali \& P. Yupapin, (2012), "THz frequency generation using MRRs for THz imaging", in International Conference on Enabling Science and Nanotechnology (EsciNano), Kuala Lumpur, Malaysia, $1-2$. 